\title{
Determinants of regional female labour market participation in the Netherlands
}

\section{A spatial structural equation modelling approach}

\author{
An Liu • Inge Noback
}

Received: 7 July 2009 / Accepted: 1 April 2010 / Published online: 24 June 2010

(C) The Author(s) 2010. This article is published with open access at Springerlink.com

\begin{abstract}
The paper analyses the determinants of female labour participation. Structural equation modelling is used to handle theoretical concepts and to solve the typical problem of multicollinearity. The proposed methodology is applied to a dataset for the year 2002 made up of a sample of 278 municipalities in the Netherlands. The structural model and measurement model of the latent variables are estimated simultaneously by means of maximum likelihood. Model estimation and tests are performed using LISREL. Female participation is found to be positively influenced by the added-worker effect and negatively by the discouraged worker effect. The results show a negative impact of demographic pressure and a positive impact of socio-economic status and female-dominated sector structure.
\end{abstract}

JEL Classification $\mathrm{J} 16 \cdot \mathrm{C} 31 \cdot \mathrm{C} 51 \cdot \mathrm{R} 23$

\section{Introduction}

Since the 1970s the share of employed women in the Dutch labour market has increased rapidly. In the 1960 s only $25 \%$ of the women were employed, whereas in $200559 \%$ of the women had a paid job. This increase was largely the result of married women entering the labour market between the 1970s and 1980s (De Graaf and Vermeulen 1997). During the process of modernisation since 1970s Dutch women are increasingly higher educated, more career oriented, increasingly independent, and they try to synchronise work and family formation (OECD 2002). Changes on the demand side of the Dutch

\footnotetext{
A. Liu $(\varangle) \cdot$ I. Noback

Urban and Regional Studies Institute, Faculty of Spatial Sciences,

University of Groningen, P.O. Box 800, 9700 AV Groningen, The Netherlands

e-mail: an.liu@rug.nl

I. Noback

e-mail: i.noback@rug.nl
} 
labour market also contributed to the increase in female participation. The increase in employment no longer occurs in agriculture and manufacturing but has shifted towards services, where women can find jobs more easily. Furthermore, that a much broader variety of employment and working-time arrangements have become available led to a strong increase of part-time jobs. In the Netherlands, the majority of employed women work in part-time jobs to combine paid work with taking care of children. Despite the rapid increase in female participation nationally, there are significant regional differences. In 2002 the average female participation was 52\%, ranging from 34\% in the municipality Laren to $70 \%$ in Ouder-Amstel (Statistics Netherlands 2002).

This paper analyses the determinants of female labour participation in Dutch municipalities in 2002. The main reason for our study to focus on female labour participation at the municipality level is that according to Elhorts (1996b) there is no "national" labour market, due to the heterogeneous nature of labour supply and demand. Instead, there are submarkets which can be classified by types of firms and industry, job types, types of workers and especially the locations of economic actors. Employees and employers usually have access to particular submarkets only (Elhorts 1996b). The limited spatial range of labour market behaviour is clearly illustrated by the fact that people in general are only willing to accept a limited daily commuting time (see for example Van Ham 2002; Turner and Niemeier 1997). Since there are no data available for local labour market areas, we analyse municipality data. Studying participation rates at the municipal level allows for a detailed description of the spatial variation in labour force participation. However, analysis at the municipal level makes it necessary to take into account the presence of commuter flows, which indicates the presence of a larger labour market and implies spatial dependence between municipalities.

In order to get insight into the determinants of regional variation of female labour participation at the municipality level, we adopt a spatial structural equation model (SEM) including both observed and theoretical constructs (often referred to as latent variables). A SEM allows simultaneous handling of observed and latent variables within one model framework. Observed variables, such as the presence of day care and after school care facilities, possess direct empirical meanings derived from experience and can be directly measured. Latent variables or theoretical constructs, on the other hand, refer to those phenomena that are supposed to exist but cannot be observed directly. A well-known example is socio-economic status. It refers to an individual's standing in the society, which cannot be observed or measured directly. However, it can be measured via observable indicators like educational attainment, occupational status, income, etc.

The use of a SEM has several advantages. First, it leads to a closer correspondence between theory and empirics because it gives latent variables empirical meanings by means of operational definitions (Oud and Folmer 2008). Second, it may reduce multicollinearity because the strongly correlated observed variables that are indicators of an underlying latent variable are substituted by latent variables in the structural model whereas they are dependent variables in the measurement model.Third, it allows accounting for measurement errors in the explanatory variables and thus reduces bias towards zero (Jöreskog and Sörbom 1996; Folmer and Oud 2008).

The paper is organized as follows. In Sect. 2 the conceptual model is presented on the basis of a literature review. Section 3 gives a brief introduction to structural 
equation modelling. The empirical results of the analysis are discussed in Sect. 4. Section 5 concludes and discusses some policy implications.

\section{Conceptual model}

Most studies that focus on explaining regional variation of labour force participation depart from a theoretical framework based on the neoclassical model of individual labour supply (see among others Evers and Veen 1983; Elhorts 1996a). The individual participation decisions, derived from a static model of choice between consumption and leisure, are aggregated to obtain an explanatory model of regional participation rates (Elhorts 1996b; Elhorts and Zeilstra 2007). According to Elhorts (1996b) the regional participation rate can be interpreted as the proportion of people who are willing to work at the current wage, controlling for a broad range of micro variables such as price of consumption, taxes and non-wage income, and socio-economic characteristics like age, education and household situation. However, Elhorts (1996b) also argues that studies on regional labour market participation generally do not limit themselves to the microeconomic model, but also focus on possible relationships between labour participation and local variables related to work and residence. Van der Laan and van der Bout (1990), for example, argue that regional variation in female participation rates is influenced by the heterogeneity of potential participants in the labour market and by the regional (labour market) context. Similar to Van der Laan and van der Bout (1990) we adopt an eclectic approach and develop a model based on an extensive literature review, including Elhorts (1996b) who presents an overview of 17 empirical studies in which participation rates have been estimated using regional data.

\subsection{Micro-level characteristics}

The wage level is assumed to have a positive effect on female labour market participation. This follows from the neoclassical model of individual labour supply which analyses the choice between actual hours of work and leisure on the basis of the theory of consumer behaviour, where leisure and work are weighed against each other (see among others Groot and Pott-Buter 1993; Cörvers and Golsteyn 2003; Henkens et al. 2002). Veen and Evers (1984) argue that at the aggregate level an increase in wages tends to have a positive labour supply effect. Employed will stay in the workforce and those who are not active are stimulated to participate (Only for wages well above average the labour supply curve will be backward-bending).

Educational attainment is postulated to have a positive effect on job opportunities according to 'Human Capital' theory (Becker 1962). In general, higher education results in better access to interesting jobs and higher wages and consequently in higher opportunity costs of choosing not to work (see among others OECD 2002; Callens et al. 2000). Some authors discuss the effect of education on labour participation in more detail. Elhorts and Zeilstra (2007) argue that higher educated have favourable labour market characteristics and are less prone to layoffs as they possess skills that are more often in demand. Moreover, they are likely to search more efficiently and successfully, to look for self fulfilment and to be more career-oriented 
(see among others Siegers and Zandanel 1981). Furthermore, higher income makes it easier to organize individual arrangements for paid help and childcare (Elhorts and Zeilstra 2007; Van der Laan and van der Bout 1990; Siegers and Zandanel 1981).

According to Vlasblom and Schippers (2004) participation rates first rise with age and start to decline after a certain age. Young individuals participate less because they are still in education and older people participate less because they retire, become disabled or do not succeed in finding new jobs after they have been laid off. Hence, the age-specific employment pattern tends to follow an inverted-U curve (Elder and Johnson 1999; Fitzenberger et al. 2004).

For women there is a strong relation between labour market participation and the presence of children (see among others Siegers and Zandanel 1981; Molho and Elias 1984; Vlasblom and Schippers 2004). Research by Vlasblom and Schippers (2004) showed that participation rates go down considerably after the birth of the first child. Moreover, longer periods with young children lead to lower participation rates due to the strong preference of Dutch women to take care of their own children (Vlasblom and Schippers 2004). This becomes apparent in several different ways. Typically Dutch is the one-and-a-half earner model in which men are the main breadwinners and women are the primary caregivers and combine paid work with household responsibilities by working part-time (De Meester et al. 2007). Furthermore, data for the Netherlands shows that 60 per cent of the households with children aged 12 or younger, with at least one of the parents working 12 hours a week or more, do not use childcare (Te Riele 2006). If women decide to withdraw from the labour force permanently, the agespecific employment pattern will take the shape of a left-hand peak curve. If withdrawal from the labour force is only temporary, during child raising ages, the age-specific employment pattern will show an M-shaped curve with a clear dip in participation around the age of 30-35 (Plantenga 1997; Fitzenberger et al. 2004). The employment curve for Dutch women resembles an M-shaped curve with two peaks; one for the age group 25-30 and a lower one for the age group 45-50 (Statistics Netherlands 2002).

The provision of care is not necessarily limited to taking care of children but can also refer to taking care of other dependent relatives (Moen and Yan 2000). In a rapidly ageing society dependent elders require an increasing amount of care. Since women are the main care providers, not only with regard to taking care of children but also providing volunteer aid for elders, ageing poses a threat to female labour participation.

Finally, the relation between labour participation and homeownership is also discussed by several authors (Van der Laan and van der Bout 1990; Siegers 1976; Bowen and Finegan 1969). Buying a house requires that a high enough income is maintained to qualify for a mortgage. Therefore, a positive relationship is expected between homeownership and participation.

\subsection{Regional labour market characteristics}

According to Elhorts and Zeilstra (2007) one of the advantages of using regional data over micro-data is that individual labour market decisions are often influenced by regional characteristics such as the local labour market. Similar to most European 
countries, in the Netherlands labour adjustments due to changes in labour demand mainly take place via changes in the participation rates and not via migration of workers, as is often the case in the US (Broersma and van Dijk 2002). The regional unemployment rate and the sectoral composition of employment are used most frequently to describe the local labour market situation. In the overview provided by Elhorts (1996b) all except one of 17 studies include the regional unemployment rate in their analyses. The sign of unemployment is a priori unknown, but in general a positive effect of unemployment is interpreted as an additional-worker effect and a negative effect as a discouraged worker effect (see among others Euwals et al. 2007; Elhorts 1996b; Veen and Evers 1984). The additional-worker effect occurs when the household income drops to a critically low level due to long-term unemployment of the main breadwinner (who is usually male). In this situation, the partner (usually female) is forced to find a job to keep the household income at an acceptable level (Lundberg 1985). The discouraged worker effect is defined as the decision to refrain from job search as a result of poor chances on the labour market (Van Ham 2002). High unemployment rates in a tight labour market increases the competition for jobs. In this context job seekers might get discouraged and decide to stop their search effort. Especially women have been found to be sensitive to the discouraged worker effect (Van Ham 2002).

The second indicator frequently used to describe the local labour market situation is the sectoral composition of employment (e.g. Elhorts 1996a). Bowen and Finegan (1969) first introduced the sectoral composition of employment "designed to measure structural differences between metropolitan areas in the relative abundance of those jobs commonly held by females" (p479). Regions with a relative abundance of so-called female-dominated sectors like education and government or healthcare are expected to show higher female participation.

\subsection{Other regional characteristics}

Elhorts (1996b) observes that other variables than the ones discussed above are used to explain regional participation rates as well. Based on this literature review we include commuting behaviour and childcare facilities. A majority of the literature indicates that employed women tend to have shorter commute-to-work distances and times than employed men (see among others Camstra 1996; Hanson and Pratt 1988; Turner and Niemeier 1997). Camstra (1996) provides two main arguments that explain women's preference for shorter commuting distance. First, women usually work fewer hours per day and generally have lower wages, making commuting relatively more expensive and time consuming. Moreover, they are overrepresented in lower-status service jobs, which are easier to find nearby, since they are more widespread. Second, women are more inclined to do a larger share of unpaid work, which makes it more difficult to allocate their time. In the Netherlands both women and men spend about an equal amount of time travelling, partly because women make more short trips either on foot or by bike and men travel further, usually by car (Molnár 2005).

Despite significant changes in gender roles, several studies have indicated that women are still primarily responsible for household task including taking care of 
children or other dependent relatives (SCP 1999; Moen and Yan 2000). This also applies to double-income households. This implies good geographical access to highquality childcare facilities might be especially relevant for the employment opportunities of mothers (Van Ham and Mulder 2005).

\section{Methodology}

The dataset we analyse contains several highly correlated variables that basically refer to underlying theoretical concepts (also denoted latent variables). For example, the variable "female-dominated sector" could be perceived as a latent variable with observed indicators the share of jobs in healthcare and the share of jobs in education and government. Inclusion of the highly correlated observed variables in a regression model is likely to lead to multicollinearity, and, hence, to the increase of the estimated variances of the estimators of the coefficients of the collinear observed explanatory variables and to incorrectly dropping variables from the model (Oud and Folmer 2008). A solution to the problem is to replace the observed variables by latent variables and to apply a SEM.

A SEM is a system of equations model. The structure includes two parts: (i) the structural model presenting the causal relationships between exogenous and endogenous latent variables as well as the relationships among latent endogenous variables mutually and (ii) the measurement model showing the relationships between the latent variables and their indicators (Folmer and Oud 2008).

A SEM in general form consists of three basic equations:

$$
\begin{aligned}
& \mathrm{y}=\Lambda_{\mathrm{y}} \eta+\varepsilon \quad \text { with } \operatorname{cov}(\varepsilon)=\Theta_{\varepsilon} \\
& \mathrm{x}=\Lambda_{x} \xi+\delta \quad \text { with } \operatorname{cov}(\delta)=\Theta_{\delta}, \\
& \eta=\mathrm{B} \eta+\Gamma \xi+\zeta \quad \text { with } \operatorname{cov}(\xi)=\Phi, \operatorname{cov}(\zeta)=\Psi
\end{aligned}
$$

In the measurement models (1) and (2), the vectors $y$ and $x$ are observed endogenous and exogenous variables, respectively; the vectors $\eta$ and $\xi$ contain latent endogenous and exogenous variables, respectively; the matrices $\Lambda_{\mathrm{y}}$ and $\Lambda_{\mathrm{x}}$ specify the loadings of the observed variables (indicators) on the vectors of latent variables; and $\Theta_{\varepsilon}$ and $\Theta_{\delta}$ are the measurement error covariance matrices. Directly observed variables can be conveniently handled in the structural model by specifying an identity relationship between a given observed variable and the corresponding latent variable in the measurement model. ${ }^{1}$

In the structural model (3) B specifies the structural relationships among the latent endogenous variables mutually and $\Gamma$ contains the impacts of the exogenous latent variables on the endogenous latent variables. $\Phi$ is the covariance matrix of the latent

\footnotetext{
1 An alternative procedures to handle multicollinearity is the application of a two-step procedure, i.e. the application of, e.g. principle component analysis to the collinear variables as a first step and inclusion of the principle components in the regression model in a subsequent step. An important advantage of SEM compared to the two-step procedures is that it allows estimation of both the measurement and structural (regression) model simultaneously.
} 
exogenous variables and $\Psi$ the covariance matrices of the errors in the structural model. The measurement errors in $\varepsilon$ and $\delta$ are assumed to be uncorrelated with the latent variables in $\eta$ and $\xi$ as well as with the structural errors in $\zeta$.

In a SEM modelling framework parameter estimation is done by minimizing the distance between the theoretical covariance matrix (based on hypotheses relating to the model structure as specified in the parameter matrices $\Lambda_{\mathrm{x}}, \Lambda_{\mathrm{y}}, \Theta_{\varepsilon}, \Theta_{\delta}, B, \Gamma, \Phi$ and $\Psi)$ and the observed covariance matrix. Several estimators for SEM have been developed including instrumental variables (IV), two-stage least squares (TSLS), unweighted least squares (ULS), generalized least squares (GLS), fully weighted (WLS) and diagonally weighted least squares (DWLS), and maximum likelihood (ML). ML method is the most commonly used method in estimating SEM models and the default in the statistical packages like LISREL and Mx. In the following, we apply ML estimation. It maximizes the log-likelihood function:

$$
l(\theta \mid Y)=-\frac{N}{2} \ln |\Sigma|-\frac{N}{2} \operatorname{tr}\left(S \Sigma^{-1}\right)-\frac{p N}{2} \ln 2 \pi
$$

where $\Sigma$ is the theoretical variance covariance matrix in terms of the free and constrained elements in the eight parameter matrices:

$$
\Sigma=\left[\begin{array}{ll}
\Lambda_{y}(I-B)^{-1}\left(\Gamma \Phi \Gamma^{\prime}+\Psi\right)\left(I-B^{\prime}\right)^{-1} \Lambda_{y}+\Theta_{\varepsilon} & \Lambda_{y}(I-B)^{-1} \Gamma \Phi \Lambda_{x}^{\prime} \\
\Lambda_{x} \Phi \Gamma^{\prime}\left(I-B^{\prime}\right)^{-1} \Lambda_{y}^{\prime} & \Lambda_{x} \Phi \Lambda_{x}^{\prime}+\Theta_{\delta}
\end{array}\right]
$$

$S$ is the observed variance covariance matrix for given dataset $Y$.

The ML-estimator $\hat{\theta}=\arg \max l(\theta \mid Y)$ chooses that value of $\theta$ which maximizes $l(\theta \mid Y)$. Minimizing the fit function

$$
F_{M L}=\ln |\Sigma|+\operatorname{tr}\left(S \Sigma^{-1}\right)-\ln |S|-p
$$

gives the same results as maximizing the above likelihood function (Oud and Folmer 2008).

The LISREL software package also provides information on identification and contains a variety of tests and model evaluation statistics and provides modification indices which can be used as suggestions for further specification of the model (see Jöreskog and Sörbom 1996 for details).

\section{Empirical results}

In this paper the female participation rate is defined as the proportion of women of the potential female labour force in a municipality who have a job for at least $12 \mathrm{~h}$ a week. Hence, part-time jobs are included. Women who are looking for a job or temporarily recovering from an injury or illness are excluded, though. Observe that although unemployed women are part of the active labour force, they are generally underreported because not all women who look for a job report to an employment agency. 
We analyse participation rates by municipality for the year 2002. Ideally, we would have estimated the model based on data for all 496 municipalities. However, the required data are not available for all municipalities, in part because of the large number of explanatory variables included in the conceptual model. Especially, data for education and childcare are missing for smaller, predominantly rural municipalities.

For 2002, data on female participation are available for 377 municipalities, and data on the explanatory variables are available for 278 municipalities. The empirical model is therefore estimated for 278 municipalities, which accounts for $80 \%$ of the Dutch population. Therefore, the impact of the missing data on model results is only minor. It should be observed that we have also estimated the model for a larger set of municipalities (377) without the explanatory variables education and childcare that are missing for a substantial proportion of municipalities. There results differed only slightly from the results presented here.

The regional variation of female participation is shown in Fig. 1. It is obvious that there is considerable spatial variation in participation rates. Higher degrees of participation appear over-represented in the centre of the Netherlands and in cities including the three cities in the North of the Netherlands. The cluster of high female participation in the province of Drenthe in the North of the Netherlands can be explained by the high prevalence of health care facilities.

The considerable variation in participation, which becomes visible at a lower regional scale, strongly supports the use of smaller geographical units of analysis, in this case municipalities. However, the scale of labour markets usually exceeds the scale of municipalities because commuting flows frequently cross municipality borders on a large scale. Therefore, we have to take the labour market situation of neighbouring municipalities into account.

For wage level we use average disposable income, i.e. income after tax deductions, of women aged over 15 who received an income during an entire year. The advantage of using disposable income above the gross wage rate is that the latter does not reflect purchasing power correctly because taxes and social security payment differ per household, income and industrial sector.

We treat wage as an exogenous variable because the majority of the wages in the Netherlands are bargained under a collective labour agreement (CAO). This is a national agreement, sector-specific and does not differ between men and women (see Lommerud et al. 2000; Correa López and Naylor 2004). The fact that wages are set at the national level rather than at the regional level does not mean that average wages are largely equal across regions. Wages can vary across municipalities due to differences in regional economic structure and the cost of living, which is higher for the central and highly urban areas.

Ideally, we would include the proportion of higher educated directly but due to privacy regulations data for higher educated are incomplete. We therefore calculated a proxy for the educational level of women in a municipality as follows:

$1-\left(\frac{\text { No. of women with at least a completed primary education and the first stages of secondary education }}{\text { Female population in labour market }}\right)$

Age and family formation are measured as the proportions of women after childbearing years, aged between 35 and 45 . To take into account the effect of providing 


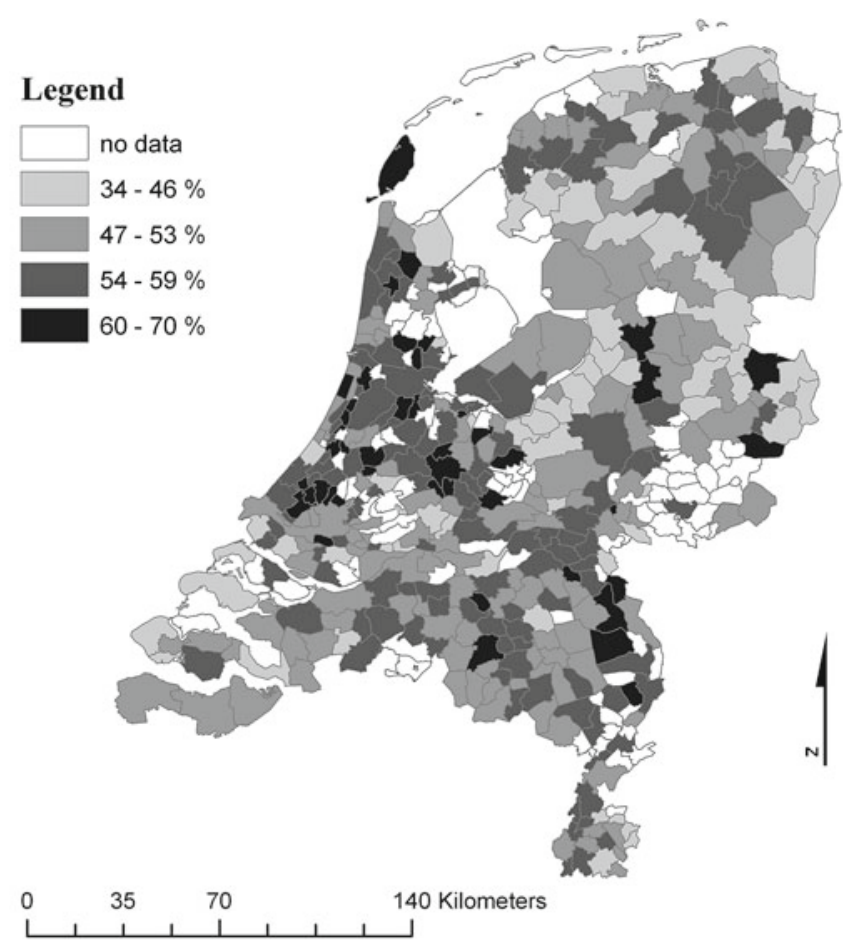

Source: Data from Statistics Netherlands

C) 2005, Statistics Netherlands / Topografische Dienst Kadaster

Fig. 1 Female participation in Dutch municipalities, 2002

care for children and elders we also include the dependency ratio defined as

$$
\frac{\text { No. of persons }<20+\text { No. of persons }>65}{\text { No. of persons 20-65 years of age }} \times 100
$$

Homeownership is measured as the proportion of owned houses.

To measure local labour market conditions, the regional unemployment rate and the share of employment in healthcare, education and government are included in the empirical model. Since male unemployment and female labour market behaviour affect each other crosswise, gender-specific unemployment rates are included in the model. The percentage of unemployed men or women is measured as the number of unemployed to the labour force. The employment data are measured by place of residence.

Other local variables included in the empirical model are commuting and childcare facilities. Commuting is measured as the average commute-to-work duration, i.e. the average time people need to commute to work. The provision of childcare is measured by (i) the availability of day care facilities for children aged 0-3, i.e. the number of 
Table 1 Descriptive statistics

\begin{tabular}{lrrr}
\hline & Mean & Std. deviation & Min-Max \\
\hline Dependent variables & & & \\
$\quad$ Female participation rate (\%) & 52.11 & 5.86 & $37.60-68.00$ \\
Explanatory variables & & & \\
Average disposable income (1000 Euro) & 13.69 & 1.18 & $11.90-18.20$ \\
Education level (\%) & 86.28 & 2.89 & $74.55-93.55$ \\
Women 35-45 years old (\%) & 15.81 & 1.12 & $13.47-19.69$ \\
Demographic pressure & 63.67 & 5.75 & $45.50-84.80$ \\
House ownership (\%) & 60.11 & 10.06 & $14.00-81.00$ \\
Unemployed women (\%) & 7.67 & 3.69 & $2.28-22.31$ \\
Unemployed men (\%) & 5.73 & 2.93 & $1.51-16.78$ \\
Jobs in healthcare (\%) & 12.56 & 6.52 & $1.67-37.85$ \\
Jobs in education and government (\%) & 10.11 & 4.97 & $2.48-40.32$ \\
Commute-to-work duration (minutes per person per day) & 11.57 & 2.24 & $7.26-21.08$ \\
Day care facilities (available slots per 100 children aged 0-3) & 18.57 & 10.69 & $0.86-69.41$ \\
After school care facilities & 5.31 & 3.26 & $0.14-21.00$ \\
$\quad$ (available slots per 100 children aged 4-12) & & & \\
\hline
\end{tabular}

day care slots times 1.7 over the number of children aged $0-3$ in a municipality ${ }^{2}$ and (ii) after school care facilities for children aged 4-12, i.e. the number of after school slots times 1.7 over the number of children aged 4-12.

Table 1 provides an overview of the descriptive statistics of the indicators included in the empirical model. A complete overview of the variables and the data sources can be found in appendix A.

\subsection{Model specification}

The SEM model we apply has only one dependent variable: female labour market participation rate. The set of explanatory variables includes both observables (e.g percentage of women aged 35-45, male and female unemployment rates) and latent variables (female-dominated sectors and socio-economic status). The indicators of female-dominated sectors are percentages of jobs (1) in healthcare, (2) in education and government, since both offer more work opportunities for females. Disposable income, percentage of higher educated females and percentage of house ownership are chosen as indicators for the second latent variable socio-economic status. Each observable represents a different aspect of socio-economic status. The observed variables are treated as single-indicator latent variables with factor loadings in $\Lambda$ fixed

\footnotetext{
2 One slot consists of 10 units (five days per week times two segments; morning and afternoon) and is on average occupied by 1.7 children. Based on oral information provided by Deloitte consultancy.
} 
Table 2 Diagnostics for spatial dependence in GeoDa

\begin{tabular}{lll}
\hline Test & Value & Prob. \\
\hline Moran's I (error) & 2.696936 & 0.006998 \\
Lagrange Multiplier (lag) & 0.925748 & 0.335970 \\
Robust LM (lag) & $5.71 \mathrm{E}-05$ & 0.993971 \\
Lagrange Multiplier (error) & 4.766236 & 0.029023 \\
Robust LM (error) & 3.840546 & 0.050027 \\
Lagrange Multiplier (SARMA) & 4.766294 & 0.092260 \\
\hline
\end{tabular}

at 1 , and the corresponding measurement errors in $\delta$ fixed at 0 (i.e., we assume no measurement error).

Since the units of observation (municipalities) are small, female labour market participation in one municipality could also be affected by some exogenous variables in neighbouring municipalities because of spillovers among municipalities and the possibility of commuting. Therefore, spatial dependence among municipalities needs to be considered. We assume first-order queen contiguity, which is represented by a weight matrix $\mathrm{W}$ where $\mathrm{w}_{i j}=1$ if municipalities share a common border or vertex and 0 elsewhere. A normalized weight matrix is used such that for each observation, the weights of the neighbouring values sums to 1 . First-order queen contiguity is considered adequate due to the fact that short distance commuting is most common in the Netherlands. We also considered alternatives to first-order queen contiguity, including second-order queen contiguity and inverse distance. ${ }^{3}$ However, the results obtained by these alternative specifications only slightly differed from the first-order queen contiguity results.

Regarding the identification of spatial dependence we proceed as follows. First we estimate the model by means of OLS applying the statistical package GeoDa (Anselin et al. 2006) which includes several Lagrange Multiplier statistics to test spatial dependence. The spatial dependence can either be the result of spatial autocorrelation of the dependent variable (spatial lag) or spatial autocorrelation in the residuals (spatial error). As Table 2 shows, the Lagrange Multiplier test indicates a spatial error model rather than a spatial lag model. Particularly, none of the Lagrange Multiplier statistics for a spatial lag model are significant. Moreover, there are no substantive arguments for a spatial lag model (i.e. a spatially correlated dependent variable), since the participation rate in one region cannot directly affect the participation in other regions. However, there are substantive arguments for a spatial error model due to spatial spillover of supply and demand of labour among regions. For instance, female labour supply in a given region may be influenced by female and male labour supply and demand in neighbouring regions.

Figure 2 presents the path diagram of the final SEM participation model estimated. Some variables that were discussed in the theoretical framework were left out of the final model. Explanations for the deletion follow below.

\footnotetext{
3 As observed above, commuting in the Netherlands is mainly over short distances which renders secondand higher order contiguity and inverse distance implausible.
} 


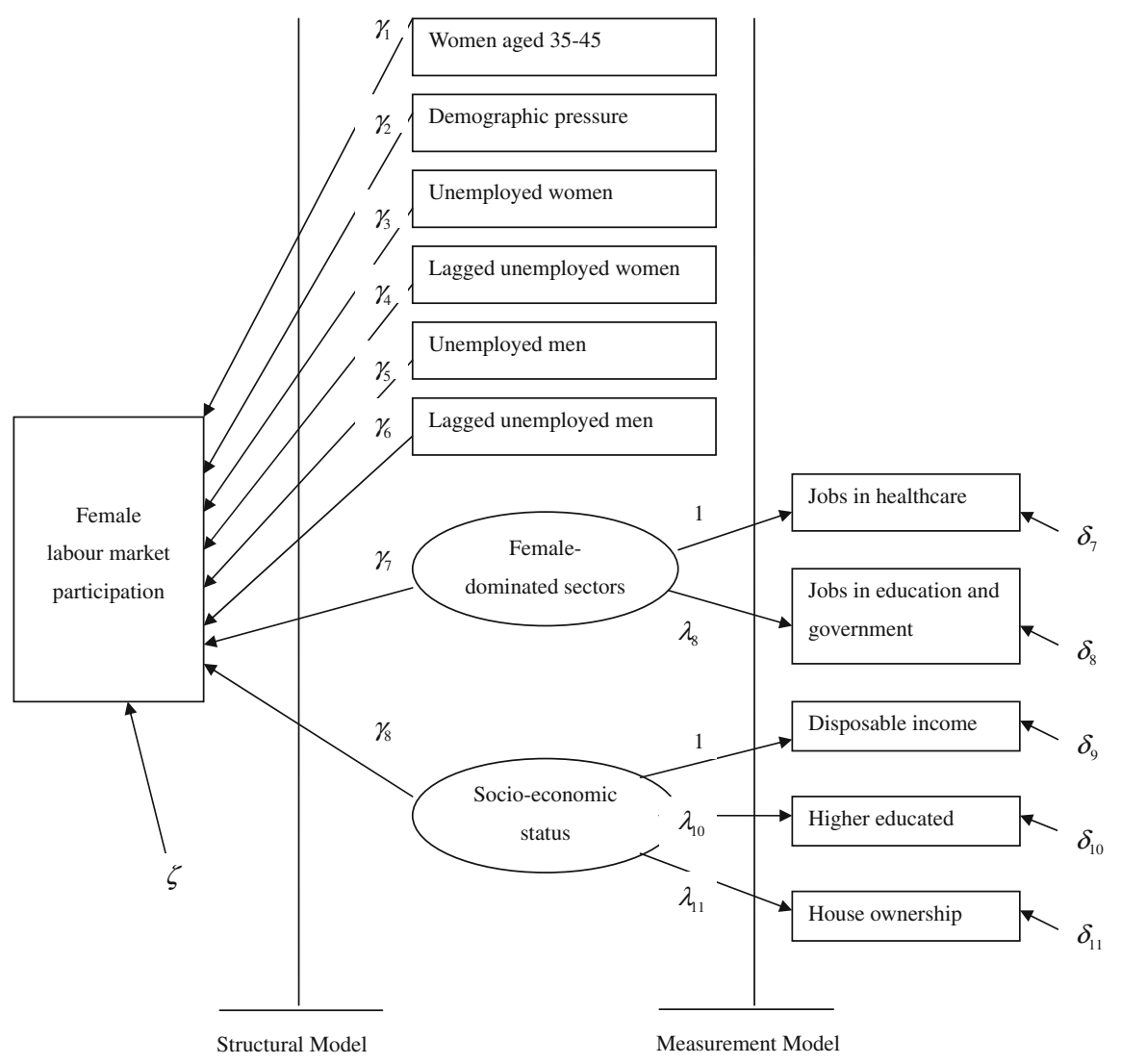

Fig. 2 Path diagram of the SEM female participation model

\subsection{Estimation results}

The $\chi^{2}$ value for the combined measurement and structural model (overall fit) is 74.28 with degrees of freedom $d f=19(p=0.00)$. However, the likelihood ratio test is sensitive to sample size and deviations from normality and therefore not quite appropriate. A popular alternative SEM model fit measure, which is based on the $\chi^{2}$ but less sensitive to the aforementioned deviations, is the RMSEA (root mean square error of approximation). The RMSEA value for our model is 0.097 with a $90 \% \mathrm{CI}=(0.073 ; 0.122)$, which indicates a reasonable overall fit (Browne and Cudeck 1993). Moreover, other model judgement statistics such as the modification indices which give hints that some coefficients have been incorrectly fixed or constrained (Jöreskog and Sörbom 1996) support the overall model fit. Particularly, there are no indications that coefficients have incorrectly been fixed at zero. (The matrix of modification indices is available upon request from the corresponding author.)

We now turn to the measurement model of the exogenous variables presented in Table 3 . Table 3 displays the $R^{2}$ values, coefficients, standard errors and z-statistics of 
Table 3 LISREL estimates of the measurement model

\begin{tabular}{lllll}
\hline Variable & Coefficient & Std. Error & z-Value & $R^{2}$ \\
\hline Female-dominated sectors & & & & \\
$\quad$ Jobs in healthcare (\%) & 1 & 0.028 & 28.79 & 0.86 \\
$\quad \begin{array}{l}\text { Jobs in education and government (\%) } \\
\text { Socio-economic status }\end{array}$ & $0.80^{* * *}$ & & & 0.86 \\
$\quad$ Disposable income & 1 & & & 0.99 \\
$\quad$ Higher educated (\%) & $0.63^{* * *}$ & 0.003 & 218.78 & 0.99 \\
House ownership (\%) & $0.44^{* * *}$ & 0.006 & 79.01 & 0.97 \\
\hline$* * * p<0.01$ & & & &
\end{tabular}

the measurement model. The $R^{2}$ values are squared multiple correlations indicating the percentage of the variance of a latent variable explained by the indicator. The $R^{2}$ values are all very high $(0.86-0.99)$ indicating that the reliability of the indicators is very high.

The coefficients are factor loadings indicating the weight each indicator carries in defining the corresponding latent variable. For each latent variable, the coefficient of first indicator is fixed at 1 to fix the measurement scale of each latent variable so as to render the model identified (Jöreskog and Sörbom 1996). The factor loadings for the second and third indicators of both latent variables are significant at $1 \%$ level with values less than 1 , indicating that the second or third indicator does not contribute as much as the first indicator in defining the latent variables. Moreover, the third indicator-house ownership (0.44) - is less important than the second indicatorhigher educated (0.63) — in defining socio-economic status.

The structural model presented in Table 4 is the outcome of a stepwise procedure. We started off with a model including all the variables in the theoretical model. Next variables which were highly insignificant were excluded one by one. The final model does not include commuting behaviour because it was insignificant. Childcare was excluded from the model due to measurement issues. Similar to Van der Laan and van der Bout (1990) we found a negative significant effect of childcare, which seems counter-intuitive. In their study childcare was excluded from the analysis because the indicator they used to measure the availability of childcare was a combination of various types of childcare and the result was therefore difficult to interpret. Other studies have also raised concerns about the proper way to measure the effect of childcare on female participation. Van Ham and Büchel (2004) found that the density of regional childcare is less important than its perceived quality. At this moment we do not have indicators to adequately measure the quality of childcare provided or the accessibility to childcare on female participation.

Table 4 shows the estimated coefficients, standard errors, z-statistics and $R^{2}$ value of the structural model. The $R^{2}$ value of 0.72 indicates that about $72 \%$ of the variation in female participation is explained by all the explanatory variables in the structural model together.

The results indicate a positive significant relation between socio-economic status and female participation, as hypothesized in Sect. 2. As expected, there also is a positive 
Table 4 LISREL estimates of the structural model

\begin{tabular}{lccr}
\hline Variable & Coefficient & Std. Error & z-Value \\
\hline Socio-economic status & $3.58^{* * *}$ & 0.92 & 3.89 \\
Women 35-45 years old (\%) & $1.98^{* * *}$ & 0.42 & 4.66 \\
Demographic pressure & $-2.84^{* * *}$ & 0.55 & -5.18 \\
Female unemployment (\%) & $-1.14^{* * *}$ & 0.22 & -5.37 \\
Lagged female unemployment (\%) & $0.80^{* * *}$ & 0.30 & 2.63 \\
Male unemployment (\%) & $0.85^{* *}$ & 0.34 & 2.51 \\
Lagged male unemployment (\%) & $-1.14^{* * *}$ & 0.40 & -2.84 \\
Female-dominated sectors & $0.53^{* *}$ & 0.24 & 2.24 \\
Constant & -12.22 & 11.46 & -1.07 \\
$R^{2}$ & & & 0.72 \\
\hline
\end{tabular}

significant relation between the proportion of women aged 35-45 and female labour market participation. In other words, municipalities with a larger share of women in the age group 35-45, an age-group also referred to as 'after childbearing years', have higher levels of female participation. This follows from the fact that taking care of children becomes less intensive as they grow older and women return to the labour market.

Furthermore, the results show a significant negative relation between demographic pressure and female participation. Municipalities with a larger share of children and elders, i.e. higher demographic pressure, have lower female participation rates. This study confirms earlier studies where it was found that Dutch women prefer to take care of their own children (Vlasblom and Schippers 2004).

The results indicate a negative significant relationship between female unemployment rate and female participation in the home municipality. The negative relation is in line with the theoretical notion of the discouraged-worker effect, i.e. the tendency to refrain from searching for a job due to perceived poor chances on the labour market. For lagged female unemployment (i.e. the average share of unemployed women for neighbouring municipalities), we found a positive relation. This is an unexpected result for which no clear explanation is available. A possible explanation could be that the lagged unemployment rate is viewed as an indication of deteriorating employment opportunities in general which induces those females who are interested in getting employed to increase job searching which in its turn leads to a higher employment rate. Needless to say, this heroic assumption needs further investigation, particularly at the micro level.

The relationship between male unemployment and female participation is positive and significant, indicating an additional-worker effect. This means that municipalities with high shares of unemployed men have relatively higher female participation rates. The rationale is that if men are unable to find a job, wives are induced to take up jobs to keep the household income at an acceptable level. Since women usually do not compete with men for the same jobs female participation tends to increase with higher shares of unemployed men. For the lagged male unemployment we found a negative relation, which can be interpreted as a discouraged-worker effect. Relatively higher average levels of male unemployment in neighbouring regions can be perceived as a general indication of poor chances on the labour market. Since women are more 
sensitive to the negative labour market situations and could more easily get discouraged, they tend to refrain from job search for increasing levels of male unemployment in neighbouring regions.

As expected, we found a positive significant relationship between female-dominated sector structure and female participation. As discussed in Sect. 2, women tend to search for jobs nearby to limit commuting duration; therefore, a favourable local labour market situation tends to increase female participation.

\section{Conclusions and policy implications}

The aim of this paper was to gain insight into the determinants of female labour market participation at the municipal level in the Netherlands. For that purpose we applied a structural equation modelling approach which allows handling of both observed and latent variables in one model framework. Application of SEM allows a close correspondence between theory and empirics and reduces the problems of multicollinearity and attenuation due to measurement errors in the explanatory variables.

There are two latent explanatory variables in the model: female-dominated sectors and socio-economic status. The measurement model shows that the percentage of jobs in healthcare is a more important indicator of female-dominated sectors than percentage of jobs in education and government; that the proportion of higher educated females and house ownership are both less important indicators of socio-economic status than disposable income.

On the basis of the structural equation model, we identified the following positive determinants of female labour market participation: percentage of women aged 35-45, male unemployment rate, lagged female unemployment rate, female-dominated sectors and socio-economic status. Female unemployment rate, lagged male unemployment rate and demographic pressure were found to have negative impacts. Generally, the empirical findings are in line with the hypothesized theoretical model except for the unexpected relationship between lagged female unemployment rate and female participation.

The empirical findings in this paper have some interesting policy implications. The Dutch government is currently engaged in the development of new policies to increase female labour participation. The findings of this paper show that an important policy handle to achieve this goal is to make it financially more attractive for women to participate. Existing tax return regulations need to be reconsidered for this purpose. Another interesting finding is the negative relationship between childcare and female participation which is contrary to theory and intuition. The strong preference of Dutch women to take care of their children themselves might in part explain this unexpected relation. Another possibility is poor matching between facilities and expectations due to, e.g. mismatch between opening hours of childcare facilities and female working hours. This implies that not only the expansion of childcare opportunities ought to be considered but also opening hours of childcare facilities and working-time regimes.

The unexpected positive relation we found between the lagged female unemployment rate and female participation suggests that further micro-level research on the perception of female unemployment in other regions than the home is needed. 
Open Access This article is distributed under the terms of the Creative Commons Attribution Noncommercial License which permits any noncommercial use, distribution, and reproduction in any medium, provided the original author(s) and source are credited.

\section{Appendix A}

See Table 5.

Table 5 Data measurement and origin

\begin{tabular}{|c|c|c|}
\hline Variables & Measured & Origin \\
\hline Participation rates & $\begin{array}{l}\text { Employed professional } \\
\text { population as a percentage } \\
\text { of Total population ( } 3 \text { year } \\
\text { averages) }\end{array}$ & $\begin{array}{l}\text { Statistics Netherlands (CBS) } \\
\text { Based on survey of } \\
\text { professional population } \\
\text { (EBB) }\end{array}$ \\
\hline Age composition & $\begin{array}{l}\text { Women aged } 35-45 \text { (after } \\
\text { childbearing years) as a } \\
\text { percentage of the total } \\
\text { female population. }\end{array}$ & CBS \\
\hline Demographic pressure & $\begin{array}{l}\text { The share of dependent } \\
\text { children and elders over the } \\
\text { share of active population } \\
(20-65)\end{array}$ & CBS \\
\hline$\%$ unemployed & $\begin{array}{l}\text { Unemployed jobseekers as a } \\
\text { percentage of the } \\
\text { professional population }\end{array}$ & $\begin{array}{l}\text { Centre for Work and Income } \\
\text { (CWI): NWW / CBS: } \\
\text { Professional population }\end{array}$ \\
\hline $\begin{array}{l}\text { Female-dominated } \\
\text { sector structure }\end{array}$ & $\begin{array}{l}\text { Aggregate firm data of } \\
\text { healthcare, education and } \\
\text { government institutions as } \\
\text { percentage of firms in all } \\
\text { sectors }\end{array}$ & LISA \\
\hline Disposable income & $\begin{array}{l}\text { Includes people over } 15 \text { with } \\
\text { a year-round salary after tax } \\
\text { deductions }\end{array}$ & CBS \\
\hline Education & $\begin{array}{l}\text { Number of lower educated } \\
\text { over the total population of } \\
\text { that municipality }\end{array}$ & CBS \\
\hline Proportion owned houses & $\begin{array}{l}\text { Proportion of private } \\
\text { dwellings in ownership }\end{array}$ & CBS \\
\hline Duration commute-to-work & $\begin{array}{l}\text { Commute duration per person } \\
\text { per day }\end{array}$ & CBS \\
\hline Day care facilities & $\begin{array}{l}\text { Number of day care slots } * 1.7 \\
\text { (average number of } \\
\text { children per slot of } 10 \text { day } \\
\text { segments) over the number } \\
\text { of } 0-3 \text { year old children in } \\
\text { that municipality }\end{array}$ & $\begin{array}{l}\text { Deloitte consultancy: data } \\
\text { collected for the Dutch } \\
\text { ministry of social affairs } \\
\text { and employment }\end{array}$ \\
\hline After school care facilities & $\begin{array}{l}\text { Number of after school care } \\
\text { slots } * 1.7 \text { (average number } \\
\text { of children per slot of } \\
10 \text { day segments) over the } \\
\text { number of } 4-12 \text { year old } \\
\text { children in that municipality }\end{array}$ & $\begin{array}{l}\text { Deloitte consultancy: data } \\
\text { collected for the Dutch } \\
\text { ministry of social affairs } \\
\text { and employment }\end{array}$ \\
\hline
\end{tabular}




\section{References}

Anselin L, Syabri I, Kho Y (2006) GeoDa: an introduction to spatial data analysis. Geogr Anal 38:5-22

Becker G (1962) Investment in human capital: a theoretical analysis. J Political Econ 70(5):9-49

Bowen WG, Finegan TA (1969) The economics of labor force participation. Princeton University Press, Princeton

Broersma L, van Dijk J (2002) Regional labour market dynamics in The Netherlands. Papers Reg Sci 81(3):343-364

Browne MW, Cudeck R (1993) Alternative ways of assessing model fit. In: Bollen KA, Long JS (eds) Testing structural equation models. Newbury Park, Sage, pp 136-162

Callens M, van Hoorn W, de Jong A (2000) Labour force participation of mothers. In: De Beer J, Deven F (eds) Diversity in family formation: the 2nd demographic transition in Belgium and the Netherlands, vol 8, issue 5. European Studies of Population, pp 89-139

Camstra R (1996) Commuting and gender in a lifestyle perspective. Urban Stud 33(2):283-300

Correa López M, Naylor RA (2004) The Cournot-Bertrand profit differential: a reversal result in a differentiated duopoly with wage bargaining. Eur Econ Rev 48(3):681-696

Cörvers F, Golsteyn B (2003) Changes in women's willingness to work in a tightening labour market: the impact of preferences, wages and individual characteristics. ROA Research Memorandum 2003/5E

De Graaf P, Vermeulen H (1997) Female labour market participation in the Netherlands: developments in the relationship between family cycle and employment. In: Blossfeld HP, Hakim C (eds) Between equalization and marginalization: women working part-time in Europe and the United States of America. Oxford University Press, Oxford, pp 191-209

De Meester E, Mulder CH, Droogleever Fortuijn J (2007) Time spent in paid work by women and men in urban and less urban contexts in The Netherlands. TESG 98(5):585-602

Elder S, Johnson LJ (1999) Sex-specific labour market indicators: what they show. Int Labour Rev 138(4):447-464

Elhorts JP (1996a) A regional analysis of labour force participation rates across the member states of the European Union. Reg Stud 30(5):455-465

Elhorts JP (1996b) Regional labour market research on participation rates. TESG 87(3):209-221

Elhorts JP, Zeilstra AS (2007) Labour force participation rates at the regional and national levels of the European Union: an integrated analysis. Papers Reg Sci 86(4):525-549

Euwals R, Knoef M, van Vuuren D (2007) The trend in female labour force participation: what can be expected for the future? IZA discussion paper 3225

Evers G, Veen A (1983) A simultaneous model of regional labor supply incorporating labor force participation, commuting and migration. Socioecon Plan Sci 17(5-6):239-250

Fitzenberger B, Schnabel R, Wunderlich G (2004) The gender gap in labor market participation and employment: a cohort analysis for West Germany. J Popul Econ 17(1):83-116

Folmer H, Oud JHL (2008) How to get rid of W? A latent variables approach to modeling spatially lagged variables. Environ Plan A 40:2526-2538

Groot W, Pott-Buter H (1993) Why married women's labour supply in the Netherlands has increased. Economist 141(2):238-255

Hanson S, Pratt G (1988) Reconceptualizing the links between home and work in urban geography. Econ Geogr 64(4):299-321

Henkens K, Grift Y, Siegers J (2002) Changes in female labour supply in the Netherlands 1989-1998: the case of married and cohabiting women. Eur J Popul 18:39-57

Jöreskog KG, Sörbom D (1996) LISREL 8: user's reference guide. Scientific Software International, Chicago

Lommerud KE, Straume OR, Sorgard L (2000) Merger Profitability in Unionized Oligopoly (Departmental Working Papers). Department of Economics, UCSB, Santa Barbara

Lundberg S (1985) The added worker effect. J Labour Econ 3(1):11-37

Moen P, Yan Y (2000) Effective work/life strategies: working couples, work conditions, gender, and life quality. Social Prob 47(3):291-326

Molho I, Elias P (1984) A study of regional trends in the labour force participation of married women in the UK, 1968-1977. Appl Econ 16:163-173

Molnár H (2005) Mobiliteit van ouders met jonge kinderen, Sociaal-economische trends 4e kwartaal, CBS

OECD (2002) Women at work: who are they and how are they faring? In: OECD Employment Outlook, pp 63-125 
Oud JHL, Folmer H (2008) A structural equation approach to models with spatial dependence. Geogr Anal 40:152-166

Plantenga J (1997) European constants and national particularities: the position of women in the EU labour market. In: Dijkstra AG, Plantenga J (eds) Gender and economics a European perspective. Routledge, London, pp 86

SCP (1999) Naar andere tijden? Tijdsbesteding en tijdsordening in Nederland, 1975-1995. Soc Cult Stud 9

Siegers JJ (1976) Participatie op de arbeidsmarkt door gehuwde vrouwen jonger dan 35 jaar in Nederland. Bevolking en Gezin 2:209-228

Siegers JJ, Zandanel R (1981) A simultaneous analysis of the labour force participation of married women and the presence of young children in the family. Economist 129(3):382

Statistics Netherlands (2002) Voorburg/Heerlen Data available from http://www.cbs.nl

Te Riele S (2006) Gebruik van kinderopvang. Sociaal-economische trends, CBS

Turner T, Niemeier D (1997) Travel to work and household responsibility: new evidence. Transportation 24(4):397-419

Van der Laan L, van der Bout ER (1990) Een Economisch-geografische Analyse van de Regionale Verschillen in de Participatie van Vrouwen op de Arbeidsmarkt in Nederland. Economisch Geografisch Instituut, Erasmus Universiteit, Rotterdam

Van Ham M (2002) Job access, workplace mobility, and occupational achievement. Eburon Publishers, Delft

Van Ham M, Büchel F (2004) Females' willingness to work and the discouragement effect of a poor local childcare provision. Appl Econ Q 4:363-377

Van Ham M, Mulder CH (2005) Geographical access to childcare and mother's labour-force participation. Tijdschrift voor Economische en Sociale Geografie: Orgaan der Nederlandsche Vereeniging voor Economische Geographie 96(1):63-74

Veen A, Evers GHM (1984) A labour-supply function for females in the Netherlands. Economist 132(3): 367

Vlasblom JD, Schippers JJ (2004) Increases in female labour force participation in Europe: similarities and differences. Eur J Popul 20(4):375-392 